\title{
Guerra e revolução: os anos de formação de A. Gramsci
}

\section{Sabrina Areco ${ }^{1}$}

https://orcid.org/0000-0003-1853-0037

${ }^{1}$ Universidade Estadual de Mato Grosso do Sul, Unidade de Amambai, Curso de Ciências Sociais, Amambai, MS, Brasil

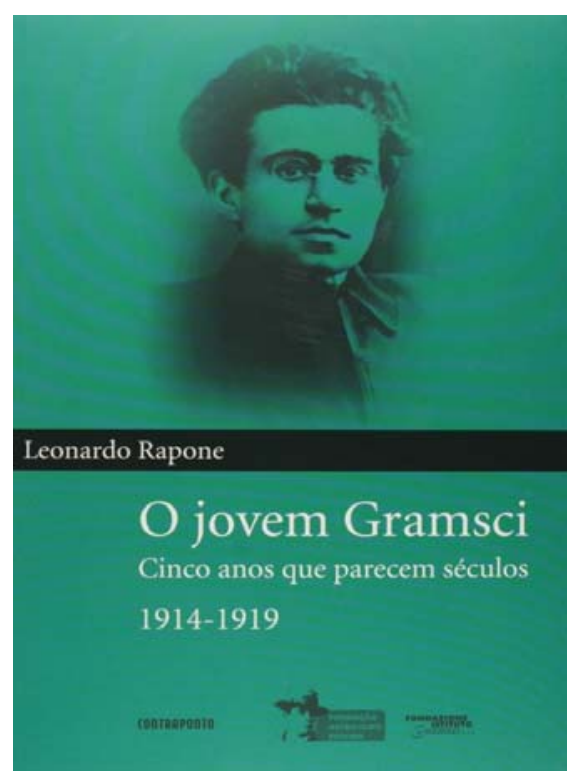

\section{RESENHA: Guerra e revolução: os anos de formação de A. Gramsci}

RAPONE, Leonardo. Ojovem Gramsci: cinco anos que parecem séculos 1914-1919. Tradução Luiz Sérgio Henriques. Rio de Janeiro: Contraponto; Brasília, DF: Fundação Astrogildo Pereira, 2014. 476 p.

\section{REVIEW: War and Revolution: A. Gramsci's Years of Education}

RAPONE, Leonardo. Ojovem Gramsci: cinco anos que parecem séculos 1914-1919. [The Young Gramsci: Five Years That Seem Like Centuries 1914-1919]. Translation Luiz Sérgio Henriques. Rio de Janeiro: Contraponto; Brasília, DF: Fundação Astrogildo Pereira, 2014. $476 \mathrm{p}$.

Recebido em 28.01.2019. Aprovado em 17.09.2019. Revisado em 29.11.2019.

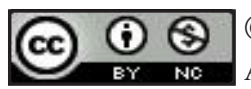

(C) O(s) Autor(es). 2020 Acesso Aberto Esta obra está licenciada sob os termos da Licença Creative Commons Atribuição-NãoComercial 4.0 Internacional (https://creativecommons.org/licenses/by-nc/4.0/deed.pt_BR), que permite copiar, distribuir e reproduzir em qualquer meio, bem como adaptar, transformar e criar a partir deste material, desde que para fins não comerciais e que você forneça o devido crédito aos autores e a fonte, insira um link para a Licença Creative Commons e indique se mudanças foram feitas. 
A obra tem como tema Antonio Gramsci (1891-1937) e seus escritos publicados na imprensa socialista italiana entre os anos de 1914 e 1919. A proposta de Rapone é delinear o que chama de "personalidade intelectual" do marxista (p. 164) e a premissa que justifica o recorte temporal é a de que este período foi fundamental na formação dessa personalidade. Como o título do livro sugere, aqueles foram anos de aceleração do tempo histórico “o período comporta a I Guerra (1914-1918), a Revolução de 1917, os movimentos grevistas em parte significativa da Europa e o Biênio Vermelho na Itália (1919-1920) - que incidiram sobre a experiência vivida por Gramsci e culminaram em sua maturidade política e intelectual. Rapone não pensa, no entanto, em uma ruptura entre o Gramsci jovem e o maduro e o demonstra ao indicar a continuidade de temas e perspectivas de análise entre os textos do período e sua obra produzida na prisão fascista - os Quaderni del carcere, redigidos entre 1929 e 1935 . Os escritos de juventude foram interpretados sob a ótica do contexto de produção, sem se recorrer, no entanto, à exposição cronológica dos artigos publicados por Gramsci.

$\mathrm{Na}$ abordagem dos textos, Rapone articula a história da Europa e da Itália no período de ascensão do fascismo, com a cuidadosa análise filológica dos textos jornalísticos e a trajetória biográfica de Gramsci. A biografia é tratada de forma a enunciar toda uma trama histórica profunda e que remete à própria formação social da Itália. Trata-se, afinal, de um homem oriundo da Sardenha, considerada pelo senso comum do período como a parte arcaica do país e folclorizada entre os socialistas reformistas na virada do século XIX-XX; que migrou em 1911 para a Turim industrializada, politicamente dinâmica e epicentro da juventude socialista intransigente. Esse confronto de dois mundos - ou entre duas Itálias, a do Norte e a Meridional - levou ao que Rapone chama de processo de "desprovincianização", marcado ainda pela convergência entre a Guerra e o início de sua militância no PSI.

Membro da comissão da IGS (International Gramsci Society), organizadora da edição nacional da obra completa de Antonio Gramsci na Itália ${ }^{1}$, Rapone nos oferece uma interpretação pautada nos debates mais recentes desenvolvidos entre os estudiosos de Gramsci no mundo. O tratamento cuidadoso do desenvolvimento da reflexão do marxista considerando sua temporalidade própria e a atenção à filologia tem orientado estudiosos na identificação da história interna dos Quaderni. Em O jovem Gramsci há uma apropriação dos resultados mais significativos desta agenda de pesquisa utilizada para os textos pré-carcerários.

O livro está organizado em cinco capítulos, além do Prólogo. Gostaria de abordar o Prólogo para em seguida expor aspectos que reputo mais relevantes a serem abordados sobre a obra. A discussão do Prólogo será por certo um pouco extensa. Isso decorre tanto da relevância do tema ali explorado na trajetória de Gramsci como também por permitir expor ao leitor a situação do PSI naquele contexto e a posição particular de Gramsci no âmbito do partido. Depois tratarei da obra de Rapone seguindo o fio temático que suscitou um debate importante no âmbito da literatura especializada: a origem do marxismo de Gramsci, isto é, suas fontes e momento a partir do qual é possível identificar a influência de Marx mais direta e formulada de maneira explícita. O ponto é particularmente relevante porque permitiu ao autor explorar as relações de Gramsci com o idealismo italiano, representado especialmente por B. Croce, e com diferentes correntes políticas em disputa no contexto entre os socialistas (como os intransigentes e os reformistas), mas também com liberais e mais tarde com o bolchevismo e o comunismo. Neste aspecto específico, isto é, as fontes do marxismo de Gramsci, colocarei questões ao autor e que dizem respeito ao papel da II Internacional e de A. Labriola ${ }^{2}$.

No prólogo, Rapone aborda um texto de Gramsci publicado no L'Ordine nuovo intitulado Neutralidade ativa e operante, em 31 de outubro de 1914. Trata-se de uma produção polêmica. Na publicação, Gramsci responde a um artigo de B. Mussolini saído semanas antes no periódico Avanti!. Então membro do PSI, Mussolini questionava em seu texto a palavra de ordem do partido socialista de neutralidade absoluta, isto é, a defesa da neutralidade total da Itália no conflito, sugerindo uma neutralidade ativa e operante. $\mathrm{O}$ artigo de Gramsci foi tratado, entre os membros do partido, como uma defesa do intervencionismo. A essa acusação não se seguiu uma resposta rápida e incisiva, ainda que em seus escritos de 1916 Gramsci expressasse vigorosamente sua posição antibélica. Entre os intérpretes de Gramsci, incluso Rapone, embora não se possa falar de intervencionismo resta ainda em aberto a interpretação daquele artigo em particular.

Tratar desta polêmica no Prólogo é interessante, pois insere de imediato o leitor no estado de confusão dos socialistas italianos no início do conflito. O esforço enfrentado com êxito por Rapone foi o de conduzir o leitor - que conhece o desfecho histórico, isto é, a ascensão de Mussolini - a um contexto no qual tal desfecho não poderia ser previsto mesmo pelo mais arguto de seus expectadores contemporâneos. Isto posto, ele afirma ser impossível concordar com as análises que meticulosamente afastaram o sardo da posição de Mussolini, assim como defender a tomada de posição de Gramsci pelo intervencionismo. Seguindo o argumento de Rapone: o artigo de Mussolini (sobre o qual Gramsci fez referência) não assinalava claramente uma defesa pela participação da Itália no conflito, o que será feito sem reserva pouco depois. E quais as ponderações de Gramsci ao texto em questão? Essa pergunta conduz a controvérsias que se apoiam em grande medida em um elemento concreto: a ausência de clareza do texto de Gramsci e sua "argumentação não linear" permitem o "cruzamento 
entre a exposição do ponto de vista do autor (Gramsci) à propósito da posição socialista sobre a guerra e a interpretação-defesa do ponto de vista mussoliniano" (p. 24).

Não obstante, Rapone considera ser clara a tentativa de Gramsci de aproximar a neutralidade absoluta, defendida pelo partido, da mentalidade reformista. Esse ponto haveria permitido uma convergência dos argumentos de Mussolini e Gramsci, em grande medida fundamentada pela concepção particular de reformismo do segundo. Ele seria definido, sobretudo, pela passividade e a neutralidade dos socialistas vista como um "alheamento do processo de fazer história" (p. 26).

Passividade-neutralidade-reformismo são conectados na argumentação, enquanto a neutralidade ativa e operante era uma fórmula que permitiria a diferenciação da posição dos socialistas daquela adotada pelo Estado italiano até 1915, quando a Península entrou no conflito. A partir de 1915 a posição de Gramsci é explicitamente crítica à intervenção da Itália na guerra, orientada pelo pacifismo humanitário defendido por nomes como Romain Rolland e Charles Peguy, considerando ainda que guerra era produto e responsabilidade da burguesia, não dos socialistas ou dos proletários.

A "má burguesia" italiana, que colocou o proletariado nas trincheiras, tem para Gramsci a dupla pecha: é burguesia e é uma má burguesia (p. 364). No Capítulo 2 Rapone indica como a classe aparece contraposta ao "tipo ideal" representada primeiro pela burguesia inglesa e mais tarde estadunidense; ao lado da crítica mais geral à Itália e aos italianos. Tal percepção acerca da burguesia estava ligada à existência de uma crise "moral" na Península, reconhecida por diferentes intérpretes. Indicando a existência de "falhas do organismo social" (p. 124) produzidas historicamente pela ausência de modernidade no país, Gramsci haveria dado uma resposta socialista à questão que passava ao largo da ideia de recomposição individual assim como do nacionalismo, que pretendia uma "regeneração" da Itália com a valorização patriótica. A posição de Gramsci era

\section{A unidade entre cultura e}

política, e teoria e revolução,

para Rapone demarcava a

\section{particularidade do socialismo}

gramsciano e seu lugar

singular no interior do

partido [...] política, desviando-se ainda daqueles que partiam da "crise moral" para chegar até a crítica (ou mesmo recusa) da democracia. Ao mesmo tempo, o socialismo de Gramsci pretendia uma reforma intelectual-moral na qual o elemento da vontade e caráter individual não eram ausentes. Ainda que dotado de um acentuado voluntarismo nesse momento, por certo a ideia de vontade não desapareceu no Gramsci maduro, quando vinculado com a reflexão sobre necessidade histórica; conexão que começou a estabelecer em 1917, animada pela experiência bolchevique e também pela própria experiência da guerra: o conflito haveria colocado novas necessidades econômicas, atualizando as bases materiais e dando condições apropriadas ao surgimento de "sentimentos novos e uma força coletiva inédita" (p. 317).

Rapone reconstrói a conexão entre a crítica ao materialismo objetivista e positivista, a ideia de vontade e o pri-

meiro momento de reconhecimento teórico de Marx explorando o artigo de 1917, Revolução contra O Capi$t a l$, no qual apontou a equivalência entre os bolcheviques e Marx (p. 311). A aproximação com Marx foi assim antecedida e, depois perpassada, pela crítica ao positivismo e determinismo entranhados no marxismo italiano. Rapone coloca a importante tensão que reside no fato de Gramsci buscar as fontes para a superação do positivismo fora do campo socialista, fundamentalmente onde havia por vezes "só um interesse especulativo pelas teorias socialistas" (p. 305).

Para o autor, é decisivo o fato de que o debate da II Internacional era conhecido de forma bastante indireta por Gramsci, sendo que ele "quase seguramente, só conhecia em primeira mão aquilo que acontecia no plano italiano" - e, por isso, ele se voltou a A. Labriola (1843-1904), também como contribuição à superação do positivismo e naturalismo (p. 62). Era uma forma de recusar grande parte dos marxismos que circulavam. Mas a aproximação com Labriola não se configurou em uma pedra angular do pensamento gramsciano. Embora a contribuísse com o enfrentamento do cientificismo e naturalismo predominante entre os socialistas, tal enfrentamento não poderia ocorrer apenas no campo teórico ou intelectual, excluindo-se a intervenção política como pretendia Labriola. Rapone defende que uma identidade entre ambos foi "forçada" por Togliatti (1893-1964) ${ }^{3}$ como forma de defender um certo ítalo marxismo capaz de contribuir com a política do PCI.

Rapone aborda cuidadosamente a pouco valorizada (ao menos entre os intérpretes brasileiros) influência de A. Tasca (1892-1960) ${ }^{4}$ em Gramsci, apesar dos conflitos que ocorreram entre os dois companheiros de partido. Ambos, no interior do PSI, foram por vezes acusados de culturalistas ou de eruditismo, justamente por não reproduzir o didatismo socialista que assumia uma postura "paternalista" em relação ao "simples operá- 
rio". Impossível não ver uma antecipação da questão dos intelectuais nos Cadernos, quando Gramsci identifica a condição de ser intelectual como um atributo de todo o homem. Desde aqueles primeiros anos a questão estava colocada, portanto, sob uma lógica da cultura como algo elaborado socialmente pela classe (não era simples acúmulo enciclopédico, mas fruto de sua capacidade analítica e reflexiva), tão mais sólida quanto maior a aderência e pertinência à classe.

A unidade entre cultura e política, e teoria e revolução, para Rapone demarcava a particularidade do socialismo gramsciano e seu lugar singular no interior do partido e o que o permitiu também "a ultrapassar o perdurante estado de guerra para investigar as transformações que a crise bélica e a experiência russa estão destinadas a produzir na vida social e política, no equilíbrio internacional e no ordenamento do capitalismo" ( $p$. 106). Seus artigos, voltados a diferentes temas, passando pelo debate cultural e crítica artística, à política imediata, ou a assuntos aparentemente desinteressados como o futebol, eram orientados sob a perspectiva da teoria e da revolução, da reflexão e da prática política militante, fios condutores da abordagem gramsciana. Esta diretiva era também adotada na leitura e apreensão de debates fora do campo socialista.

A importância do livro de Rapone consiste em ajudar a entender a gênese de formulações que se apresentarão depois nos Quaderni, mas também demonstra como essa fase jornalística tem importância própria, ainda pouco explorada. Poucas vezes se deu atenção à produção de Gramsci enquanto observador atento daquele momento decisivo da história contemporânea, marcado por uma coincidência temporal que demarcaria toda sua trajetória posterior: a migração da Sardenha rural para a moderna Turim e o início da produção jornalística com a I Guerra.

Reconstruindo fontes e debates, Rapone parece, no entanto, subdimensionar a presença da II Internacional na reflexão gramsciana. Por certo que a "ortodoxia" de Kautsky não era um ponto de apoio de suas formulações, mas o pensamento e os intelectuais da II Internacional serviram como uma contraposição ou formulação antagônica importante: não é também contra o positivismo e o determinismo que orientavam esse marxismo que é dirigido grande parte do esforço teórico e analítico do jovem Gramsci e também depois na prisão? Além de contraponto negativo, a produção teórica da II Internacional (que encerra suas atividades durante a guerra) deixou como herança, temáticas que repercutiram ainda no marxismo do século XX, quer sejam apreendidas a partir da leitura dos textos ou indiretamente, por meio dos debates políticos. A questão dos intelectuais, por exemplo. Rapone argumenta que Gramsci procurou desenvolvê-la por motivações de ordem prática (no partido eram "tratados como um peso morto uma vez que não têm uma função definida e adequada a sua capacidade", p. 345), mas é preciso considerar tanto que a orbitação dos intelectuais em torno do partido não era uma novidade histórica colocada para o PSI como também foi um tema sobre o qual Kautsky havia já refletido ${ }^{5}$, ainda que o tratamento tenha sido bastante distante daquele dado por Gramsci.

Por outro lado, se reconhecermos que o marxismo de Gramsci foi filtrado pelo idealismo (como mostra no Capítulo 1), seria preciso refletir de maneira mais pormenorizadamente sobre a afirmação de Rapone de que a relação Gramsci-Labriola foi antes produto de uma aproximação "forçada" por Togliatti do que uma efetiva influência. O ponto alto do livro é justamente a recomposição das relações de Gramsci com o neoidealismo, que permitiu a Rapone demonstrar como a trajetória de Gramsci inicia-se com o socialismo intransigente até o comunismo. Contrapõe-se assim a Losurdo ${ }^{6}$, que identificou como ponto de partida um jovem Gramsci liberal. Rapone defende que os empréstimos que realizou dos liberais idealistas foram cuidadosamente reelaborados em uma visão socialista e sempre voltados para a reflexão sobre a estratégia da classe. Assim: "não existe um Gramsci liberista ou liberal, crociano, gentiliano: existe um Gramsci que ao construir sua concepção de socialismo, assume e elabora motivos da cultura de seu tempo, reconvertendo-os e tornando-os funcionais a uma perspectiva política e histórica alternativa à original" (p. 379).

O idealismo teria antes função política do que filosófica: essa corrente lhe oferece um instrumental, cuidadosamente lapidado e depurado daquilo que não lhe serve. A partir de 1917, o marxismo e o bolchevismo assumem uma importância superior e da autonomia absoluta do pensamento ele irá reconhecer nos revolucionários russos a "liberdade de criação histórica na dialética da necessidade e da liberdade própria do marxismo de Marx (p. 315)”. A reflexão sobre necessidade histórica será então operada: era a guerra que havia propiciado condições materiais para a atuação dos bolcheviques e "ao mesmo tempo tais condições propiciaram sentimentos novos e uma força coletiva inédita" (p. 317). Uma dessas manifestações foi o movimento real de luta dos conselhos, no qual se engajou fortemente. Rapone evidencia desde as primeiras páginas do seu livro toda a relevância do conflito bélico na formação e na produção gramsciana daqueles anos. Para o autor, o fim do conflito - com inflexões fundamentais após a Revolução de 1917 “ coincide com o encerramento do primeiro momento da formação intelectual e política de Gramsci, ocorrida naqueles cinco anos que pareceram séculos. 


\section{Referencias}

RAPONE, Leonardo. Ojovem Gramsci: cinco anos que parecem séculos 1914-1919. Tradução Luiz Sérgio Henriques. Rio de Janeiro: Contraponto; Brasília, DF: Fundação Astrogildo Pereira, 2014. 476 p.

\section{Notas}

1 O autor foi responsável pela organização de Antonio Gramsci: scritti (1910-1926): 1917 em colaboração com Maria Luisa Righi e Benedetta Garzarelli, publicado em 2015 pelo Istituto della Enciclopedia Italiana. Aobra reúne os artigos de autoria identificada impressos em 1917, incluindo textos cuja publicação foi censurada, mas preservou-se os rascunhos.

2 Filósofo e homem político, foi um dos mais importantes estudiosos de K. Marx eF. Engels na Itália. Sua obra promoveu uma difusão do marxismo, acompanhada de um interpretação original resultante da polêmica contra o positivismo e determinismo e da oposição à redução do pensamento de Marx e Engels a uma filosofia da história.

3 Depois da prisão de Gramsci, torna-se secretário geral do PCI (1927), onde permanece até o fim da vida. Transferiu-se para Moscou em 1934 e foi membro do Comintern.

4 Foi, junto com Gramsci e P. Togliatti, um dos fundadores do L'Ordine nuovo. Aderiu ao PCI em 1921, foi membro do Comitê executivo do Comintern (1928) e expulso do partido em 1929.

5 Como no ensaio A inteligência e a social-democracia, publicado na Die Neue Ziet (1894-1895).

6 LOSURDO, Domenico. Gramsci, do liberalismo ao “comunismo crítico”. Rio de Janeiro: Revan, 2006.

\section{Sabrina Areco}

sabrinaareco@gmail.com

Doutorado em Ciência Política na Universidade Estadual de Campinas (UNICAMP)

Professora de Ciência Política na Universidade Estadual de Mato Grosso do Sul (UEMS/ Amambai)

\section{UEMS}

R. José Luís Sampaio Ferraz, n. 3353

Amambai - Mato Grosso do Sul - Brasil

CEP: 79990-000

\section{Agência financiadora \\ Não se aplica.}

Contribuições dos autores

Não se aplica.

\section{Consentimento para publicação}

Não se aplica.

Conflito de interesses

Não se aplica.

Aprovação por Comitê de Ética e consentimento para parti-

cipação

Não se aplica. 